\title{
Implementación de un sistema de transmisión inalámbrica de energía eléctrica a través de acoplamiento resonante magnético de campo cercano para dispositivos de bajo consumo de potencia
}

\author{
Implementation of a wireless transmission system of \\ electric energy through magnetic resonant coupling of \\ near field for low power consumption devices
}

Vinueza J., Mayorga M., Santacruz F., Zabala M., Ribadeneira J.

\begin{abstract}
This paper proposes an alternative method of wireless power supply for low power consumption devices. For the design of the antennas responsible for the transmission of energy, microstrip lines were used on a FR4 substrate (Flame Retardant 4) based on mathematical methods tested from other research contributions. Therefore, integrated circuits with MMIC (Monolithic Microwave Integrated Circuits) technology are included for the generation of radio-frequency as an energy source in the range of $16 \mathrm{MHz}$ to $23 \mathrm{MHz}$. In the reception phase, a three-stage doubling voltage circuit is required with the purpose of rectifying and amplifying the transmitted signal. The results of the implementation of the system indicate an efficiency between $20 \%$ and $30 \%$ for transmission distances up to 90 millimeters without obstacles. The performance decreases between $0 \%$ and $6.67 \%$ when crossing materials such as agglomerate, plastic, glass, expanded polystyrene, fabric and wood, however, it totally loses performance with metal.
\end{abstract}

Index Terms - Voltage Doubling Rectifier Circuit, Electromagnetic Radiation, Magnetic Resonant Coupling, Wireless Power Transfer, Microstrip, MMIC.

Resumen- El presente documento plantea un método alternativo de alimentación eléctrica para dispositivos de bajo consumo de potencia de forma inalámbrica. Para el diseño de las antenas encargadas de la transmisión de energía se emplearon líneas microstrip sobre un sustrato FR4 (Flame Retardant 4) basados en métodos matemáticos probados de otros aportes investigativos. Se emplean circuitos integrados con tecnología MMIC (Monolithic Microwave Integrated Circuits) para la generación de radio - frecuencia como fuente de energía en el rango de los $16 \mathrm{MHz}$ a $23 \mathrm{MHz}$. En la fase de recepción, se

${ }^{1}$ Vinueza J., Santacruz F., Zabala M. y Ribadeneira J. pertenecen a la Escuela Superior Politécnica de Chimborazo. Panamericana Sur km 1 1/2, Riobamba-Ecuador (e-mail: rvinueza@hotmail.es, \{m zabala fabricio.santacruz, jefferson.ribadeneira \}@espoch.edu.ec).

Mayorga M., pertenece a la Universidad Técnica de Ambato, Av de Los Chasquis, Ambato-Ecuador (e-mail: monik-mayorga@hotmail.com) requiere de un circuito doblador - rectificador de voltaje de tres etapas con la finalidad de rectificar y amplificar la señal transmitida. Los resultados de la implementación del sistema indican una eficiencia entre el $20 \%$ y $30 \%$ para distancias de transmisión de hasta $90 \mathrm{~mm}$ sin obstáculos. El rendimiento decae entre $0 \%$ y $6.67 \%$ al utilizar obstáculos como aglomerado, plástico, vidrio, poli estireno expandido, tela y madera, sin embargo, pierde totalmente el rendimiento con metal.

Palabras Claves - Circuito Doblador de Voltaje, Radiación Electromagnética, Acoplamiento Resonante Magnético, Transferencia Inalámbrica de Energía, Microstrip, MMIC.

\section{INTRODUCCIÓN}

T OS primeros registros del uso de transmisión inalámbrica de energía eléctrica data hace más de 100 años cuando Nikola Tesla desarrolla el circuito de bobina que mediante variaciones en el flujo de campo magnético se logra la transmisión de energía sin la utilización de ningún medio físico. La transferencia inalámbrica de energía es básicamente un mecanismo por el cual la energía eléctrica puede ser transmitida desde una fuente de alimentación a una carga eléctrica sin la necesidad de usar cables. Las investigaciones se han centrado en la necesidad de buscar formas más convenientes en sistema de carga eléctrica [2]. Actualmente existen varias aplicaciones de sus descubrimientos como los sistemas de transformación eléctrica a través de inducción electromagnética utilizados para el sistema de alimentación de todo tipo de artefactos en el hogar y la industria [1].

Algunas técnicas de radiación de energía hacen uso de tecnología de RF (Radio Frecuencia), las cuales transmiten la señal a través del aire mediante el uso de ondas de radio consideradas como no perjudiciales para la salud humana [3], son usualmente aplicadas para transferir inalámbricamente energía a dispositivos de bajo consumo de potencia, sin embargo, en algunos casos la baja intensidad de la señal 
recibida exige la utilización de circuitos amplificadores [4].

Propuestas de sistema de transferencia inalámbrica de energía han sido presentados por diversos investigadores quienes optan por métodos como el acoplamiento fuerte resonante magnético [5] también conocido como Wireless Electricity (Witricity), así como el acoplamiento inductivo y capacitivo convencional [6], [7] y antenas rectificadoras conocidas como rectenas [8].

El sistema planteado se basa en la técnica de acoplamiento resonante magnético de campo cercano que consiste en acoplar dos antenas de características idénticas que operan en una misma frecuencia de resonancia [3], [10] - [13], [21], [22], brinda una alternativa al problema de la utilización de cables al proponer insertar el sistema transmisor en muebles de uso cotidiano para que con un simple acercamiento de la antena receptora anexada a un dispositivo de baja potencia pueda obtener la carga necesaria para funcionar.

En la sección II se explica cada una de las etapas del sistema de transmisión inalámbrica. En la sección III se analizan los resultados mediante simulación por computadora e implementación práctica y se comparan sus valores nominales con el propósito de observar la variación existente. Finalmente, en la sección IV se presentan las conclusiones.

\section{Metodología}

En esta sección se aborda el diseño y los componentes utilizados para el sistema transmisor inalámbrico de energía.

El diseño del sistema se ha dividido en 5 etapas, ver Fig. 1, cada una descrita en las subsecciones siguientes.

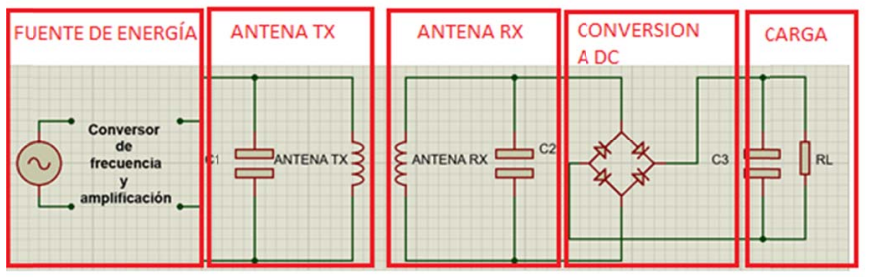

Fig. 1. Etapas del sistema transmisor de energía inalámbrica

\section{A. Fuente de energía}

La fuente de energía opera en el rango de frecuencias entre $16 \mathrm{MHz}$ a $25 \mathrm{MHz}$ y se genera mediante un oscilador con tecnología MMIC (Monolithic Microwave Integrated Circuits) controlado por voltaje y dos amplificadores de bajo ruido. Los valores de voltaje alcanzados son de $13500 \mathrm{Vpp}$ a $12600 \mathrm{Vpp}$. Se debe considerar que la variación en la amplitud es por la calidad de los integrados MMIC, ya que la amplitud de la señal disminuye inversamente proporcional a la frecuencia.

\section{B. Sistema de transmisión y recepción}

La transmisión inalámbrica de energía se lo realiza a través de dos antenas con líneas microstrip de diseño idéntico para cumplir el acoplamiento resonante magnético basado en trabajos previos [10], [12] - [14], [25] particularmente de [12] ver Fig. 2. El diseño contempla una espira que une las placas capacitivas, en el caso de la antena transmisora, la espira actúa como un lazo de alimentación y en la antena receptora recoge la energía hacia el circuito doblador - rectificador de voltaje y posteriormente a la resistencia de carga.

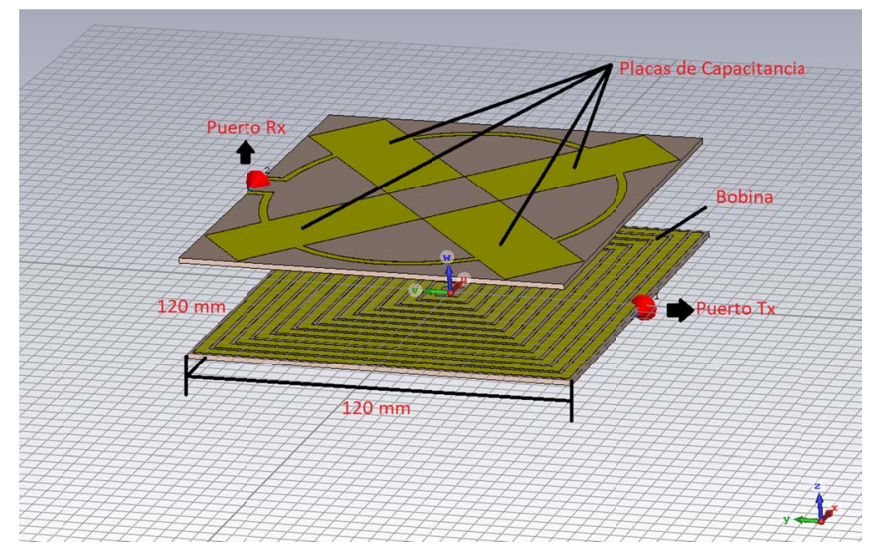

Fig. 2. Alineación de la antena transmisora y receptora separadas por el espacio libre

El circuito equivalente es de tipo Resistivo - Inductivo Capacitivo (RLC) [21], como se muestra en la Fig. 3, el mismo que permite al campo magnético del inductor colapsar e inducir la corriente eléctrica en el devanado que conduce a la carga del condensador, para que posteriormente el condensador en estado de descarga genere la corriente eléctrica resultante que crea un campo magnético en el inductor para el siguiente ciclo, el proceso se repite una y otra vez por la naturaleza de la corriente alterna que actúa como fuente [2].

La resonancia en el sistema ocurre cuando la reactancia inductiva y la reactancia capacitiva del circuito tienen la misma magnitud que da como resultado la oscilación de la energía eléctrica entre los campos eléctricos y magnéticos del condensador y el inductor respectivamente. En la resonancia, el inductor y el condensador tienen una impedancia en serie mínima y una impedancia en paralelo máxima, mientras que la reactancia inductiva y capacitiva son de igual magnitud [2].

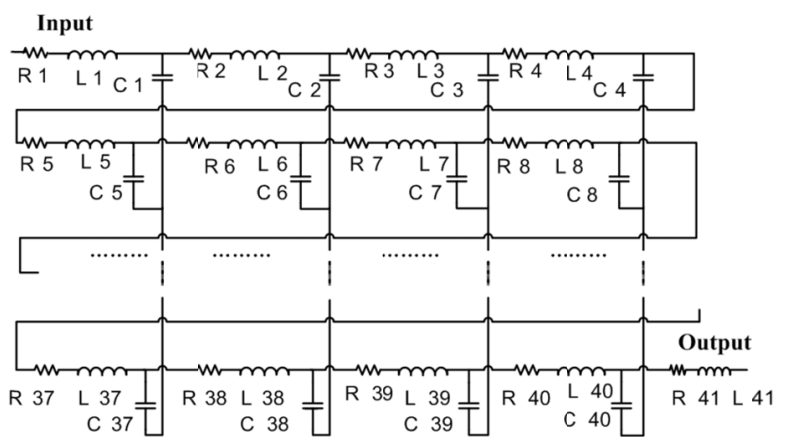

Fig. 3. Circuito equivalente RLC del sistema de transmisión y recepción [21]

En [21], el diseño del sistema de antenas resonantes se considera un circuito RLC a través del cual se obtiene la frecuencia de resonancia del sistema definido en (1):

$$
f_{r}=\frac{1}{2 \pi \sqrt{L C}}
$$


donde $f_{r}$ es la frecuencia de resonancia, $C$ es la capacitancia total del sistema y $L$ es la inductancia del sistema

La frecuencia de resonancia indica el valor de frecuencia que el sistema de antenas transfiere la mayor cantidad de potencia.

En la ecuación (1) se observa que $f_{r}$ depende fuertemente de los valores de capacitancia $C$ e inductancia $L$. Además, el valor de la capacitancia depende principalmente de las dimensiones de las tiras de cobre y del sustrato, mientras tanto, la inductancia depende del número de espiras que actúan como bobinas situadas al otro lado del sustrato.

Según [12] se escoge la forma espiral - rectangular plana para el diseño de la bobina por su facilidad de fabricación y un uso más óptimo del espacio con respecto a otras formas como la hexagonal, circular, de una sola espira, líneas serpenteantes o de alta impedancia [27].

El valor de la inductancia depende de las características de las espiras como la longitud de la tira de cobre y la geometría de la bobina. Para el efecto, se usa la fórmula de Wheeler [14]:

$$
L_{1}=K_{1} \cdot \mu_{0} \cdot \frac{n^{2}\left(d_{o u t}+d_{\text {in }}\right)}{2 \cdot\left(1+K_{2} \cdot \rho\right)}
$$

donde $L_{1}$ representa la inductancia en el puerto $1, \mu_{0}$ representa la permeabilidad en el espacio libre, $K_{1}$ y $K_{2}$ son los coeficientes de diseño que dependen de la forma de la bobina y son iguales a 2.34 y 2.75 respectivamente para una bobina espiral rectangular, $n$ representa el número de espiras de la bobina y $d_{\text {out }}$ y $d_{\text {in }}$ representan el diámetro externo e interno de la bobina respectivamente

La distancia de separación entre cada espira de línea microstrip es de $1.2 \mathrm{~mm}$ por una limitación práctica para la construcción de la antena. Considere que la distancia incide en el número total de espiras que lleva la antena y afecta a la inductancia del sistema de acuerdo al valor de $\rho$ [21], que es la relación de relleno del bobinado definido en (3), en donde un $\rho$ pequeño indica un área de cobertura de la bobina reducido y un $\rho$ grande $(\rho \approx 1)$ indica un área cubierta de la bobina mayor.

$$
\rho=\frac{d_{\text {out }}-d_{\text {in }}}{d_{\text {out }}+d_{\text {in }}}
$$

El grosor del cobre es una constante de valor de $0.035 \mathrm{~mm}$. Para observar el efecto de la inductancia se debe incrementar o disminuir el número de vueltas en las bobinas de las antenas. Se puede deducir de (2) que el incremento de espiras conduce a un aumento del valor de la inductancia lo que ocasiona que el valor de la frecuencia de resonancia disminuya según (1) [21]. El diseño de las espiras rectangulares que producen la inductancia se muestra en la Fig. 4.

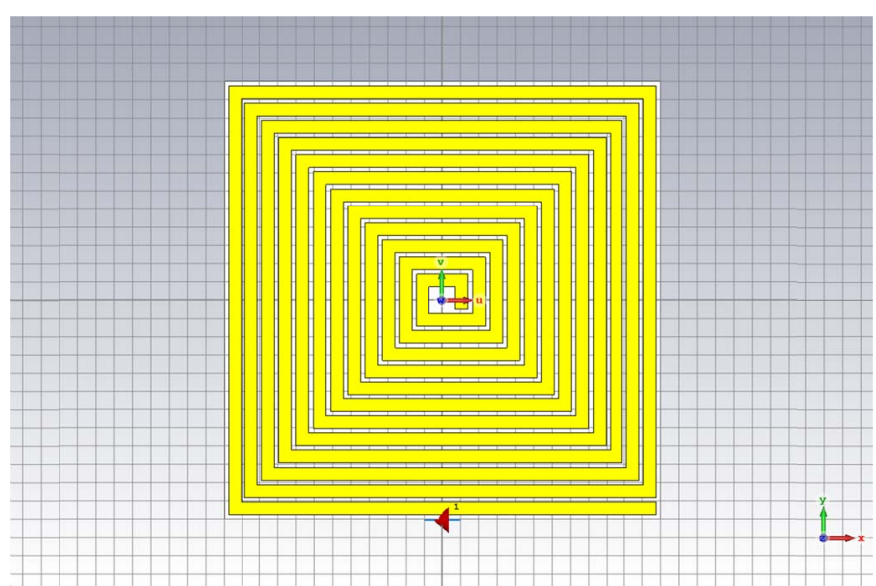

Fig. 4. Vista frontal de la antena de inductancia $1.20290 \times 10^{-5} \mathrm{H}$

En la Fig. 5 se describe la forma rectangular de las placas de cobre que producen la capacitancia. El sustrato utilizado es el Flame Retardant 4 (FR4) que cuenta con una permitividad eléctrica de $\varepsilon_{r}=4.3 \mathrm{y}$ un grosor de $1.6 \mathrm{~mm}$. La selección del sustrato FR4 se debe a su accesibilidad en el mercado ecuatoriano además del costo menor respecto a otros sustratos.

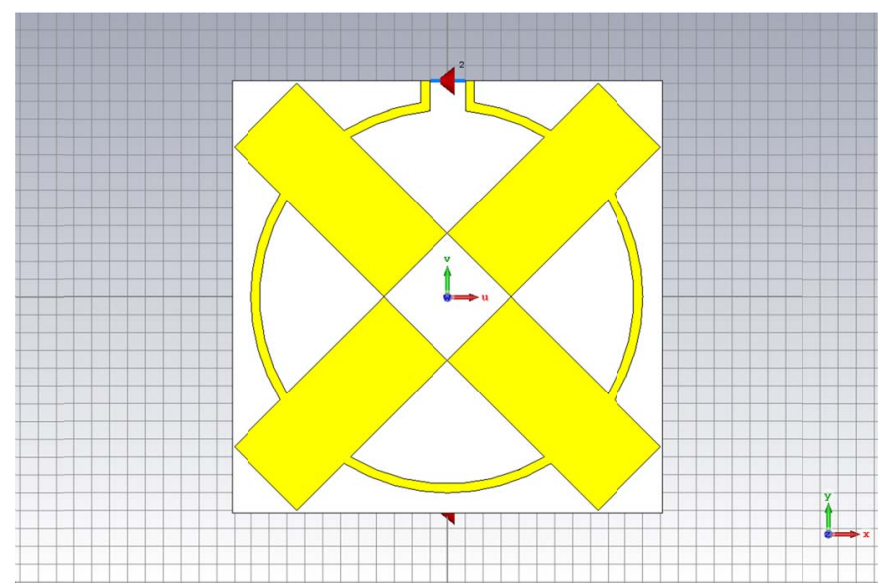

Fig. 5. Vista interna de la antena de capacitancia $3.9640625 \times 10^{-6} \mathrm{~F}$

Los cuatro rectángulos de cobre actúan como capacitores. El valor de la capacitancia $C$ [21] depende del área de cada rectángulo conductor, $A$, el grosor del aislante, $d, \mathrm{y}$ permitividad del sustrato, $\varepsilon$, mostrados en (4). El efecto de la capacitancia se manifiesta en la frecuencia de resonancia al variar su valor.

$$
C=\varepsilon \cdot \frac{A}{d}
$$

Se consideraron como valores iniciales para las dimensiones de cada rectángulo de cobre de $35 \mathrm{~mm}$ x $20 \mathrm{~mm}$, sin embargo, al utilizar (4) y luego (1) se obtuvo un valor de $f_{r}$ no óptimo, por lo que se modificaron los valores a $59 \mathrm{~mm} \mathrm{x}$ $25 \mathrm{~mm}$ para obtener una frecuencia de resonancia más baja acorde a la fuente de energía. Los valores de los rectángulos de cobre se asignaron empíricamente por parte del autor hasta encontrar una $f_{r}$ deseada.

La pérdida por inserción (insertion loss) $S_{21}$ y el coeficiente 
de reflexión (reflection coefficient o return loss) $S_{11}$ son los parámetros para analizar la eficiencia del sistema acorde con (5) y (6) [10].

$$
\begin{aligned}
& n_{11}=\left|S_{11}\right|^{2} \cdot 100 \% \\
& n_{21}=\left|S_{21}\right|^{2} \cdot 100 \%
\end{aligned}
$$

En (5) $n_{11}$ muestra la relación entre las cantidades de potencia reflejada y la entrada de potencia en el lado del transmisor, mientras que en (6) $n_{21}$ presenta las cantidades de la salida de potencia en el receptor debido a la entrada de potencia en el transmisor, ésta última se utiliza para medir la eficiencia del sistema al calcular el porcentaje de energía recibida en el lado receptor.

\section{Circuito rectificador - doblador de voltaje}

Es necesario un circuito rectificador - doblador de voltaje a la salida de la antena receptora para amplificar y convertir la señal alterna a un voltaje de corriente directa lo suficientemente fortalecida para la carga. La Fig. 6 muestra un circuito básico rectificador doblador de voltaje [4], [15]. Brevemente se describe su funcionamiento cuando ingresa el pico negativo de la fuente $A C$ el diodo $D 1$ permite el flujo de corriente al capacitor $C_{b}$, cargándolo. Cuando la misma señal $A C$ revierte la polaridad, el diodo $D 1$ se apaga y $D 2$ a su derecha permite el paso de la corriente en el sentido del diodo que carga al capacitor $C_{e}$ y que dobla la carga mantenida en $C_{b}$. El incremento en el voltaje es dos veces el voltaje de entrada, $V_{\text {out }}=V_{c c}=-2 \cdot V 1$. Debido al bajo voltaje de entrada que percibe el circuito se utilizan 3 etapas del circuito básico rectificador - doblador de voltaje con el propósito de disponer un voltaje adecuado para encender la carga.

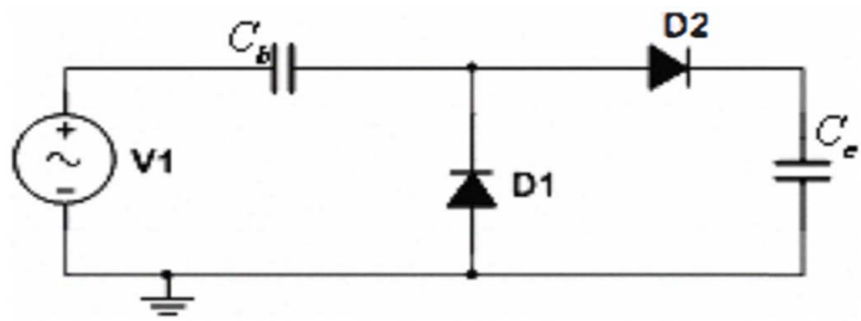

Fig. 6. Circuito básico rectificador doblador de voltaje [4]

El circuito básico rectificador de voltaje es implementado con diodos Schottky que por su alta conmutación permite detectar cambios rápidos de pico de voltaje de radio frecuencia.

\section{Carga}

Para efectos de demostración del sistema de transmisión inalámbrica de energía se utiliza como carga un Diodo Emisor de Luz común que se alimenta con la energía DC (Corriente Directa) provista por la etapa rectificadora - amplificadora.

\section{E. Medidas del sistema de transmisión inalámbrico de energía}

En la Tabla 1 y en la Fig. 7 se muestran los valores calculados para el sistema de antenas.

TABLA I

PARÁMETROS CALCULADOS EN EL DISEÑO DE LAS ANTENAS TX Y RX

\begin{tabular}{ll}
\hline \hline Parámetro & $\begin{array}{l}\text { Antenas Transmisora y } \\
\text { Receptora }\end{array}$ \\
\hline Tamaño & $120 \mathrm{~mm} \times 120 \mathrm{~mm}$ \\
\hline $\begin{array}{l}\text { Numero de vueltas de la bobina } \\
\text { espiral - rectangular }\end{array}$ & 14 \\
\hline $\begin{array}{l}\text { Ancho de las espiras de la bobina } \\
\text { espiral rectangular }\end{array}$ & $3.5 \mathrm{~mm}$ \\
\hline Espacio entre espiras & $1.2 \mathrm{~mm}$ \\
\hline Placa capacitiva & $59 \mathrm{~mm} \times 25 \mathrm{~mm}$ \\
\hline $\begin{array}{l}\text { Radio interno de la única espira } \\
\text { circular }\end{array}$ & $52 \mathrm{~mm}$ \\
\hline Ancho de la única espira circular & $2.5 \mathrm{~mm}$ \\
\hline \hline
\end{tabular}

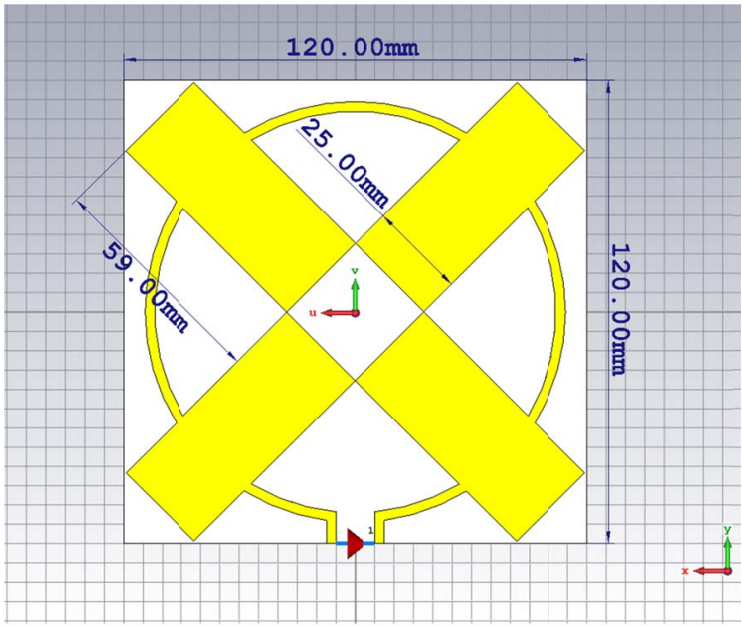

(a)

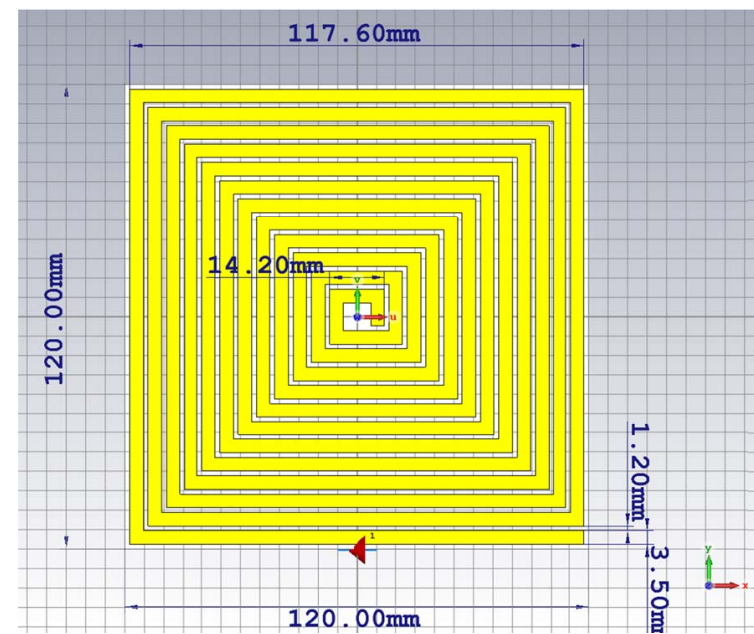

(b)

Fig. 7. Medidas de la antena transmisora/receptora de la vista interna (a) y frontal (b)

Con los datos anteriores se calculan los valores de la inductancia, capacitancia y frecuencia de resonancia del sistema, es así, que mediante (1), (2) y (4) se obtiene: $L=1.2290 \times 10^{-5} \mathrm{H}, \mathrm{C}=3.9640625 \times 10^{-6} \mathrm{~F}^{\mathrm{y}} f_{r}=23.0480 \mathrm{MHz}$. 


\section{RESULTADOS Y DISCUSIÓN}

A efectos de medición tanto el transmisor como el receptor se encuentran separados por un espacio de aire variable entre $10 \mathrm{~mm}$ y $100 \mathrm{~mm}$ para evaluar la eficiencia del sistema al introducir distintos materiales entre ellas para comprobar la versatilidad en aplicaciones prácticas.

Los resultados se obtuvieron mediante la simulación y la implementación del sistema, al final de la sección se realiza una comparación de los datos obtenidos.

\section{A. Simulación}

Los resultados de la simulación están divididos en dos partes. La primera se centra en la representación gráfica de la corriente superficial en las antenas y la segunda en los parámetros de dispersión - $S$, ambas definen la eficiencia del sistema. El software utilizado es CST Microwave Studio con licencia de prueba.

\section{1) Corriente Superficial}

En la Fig. 8 se expone la distribución de corriente en la superficie conductora en las antenas, las mismas que abarcan distancias desde los $10 \mathrm{~mm}$ hasta los $100 \mathrm{~mm}$ en pasos de $10 \mathrm{~mm}$ entre Tx y Rx. Cada figura representa la transferencia de energía a una frecuencia de resonancia correspondiente a la distancia establecida, es decir, a la máxima transferencia posible de energía en cada una de las distancias simuladas.

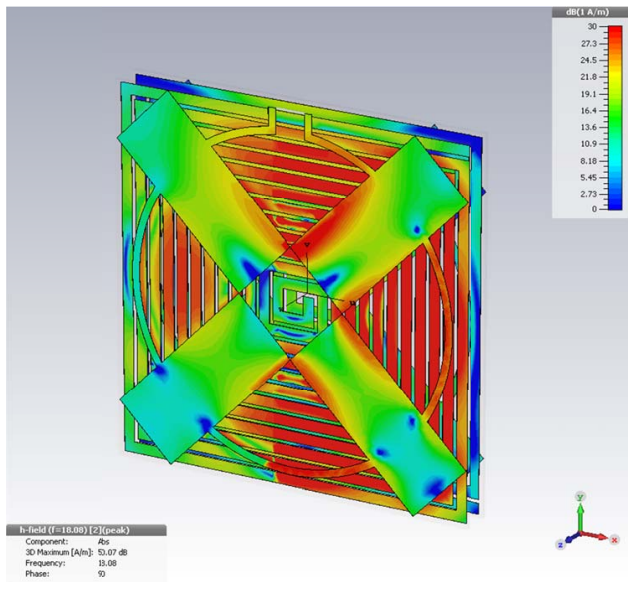

$(10 \mathrm{~mm})$

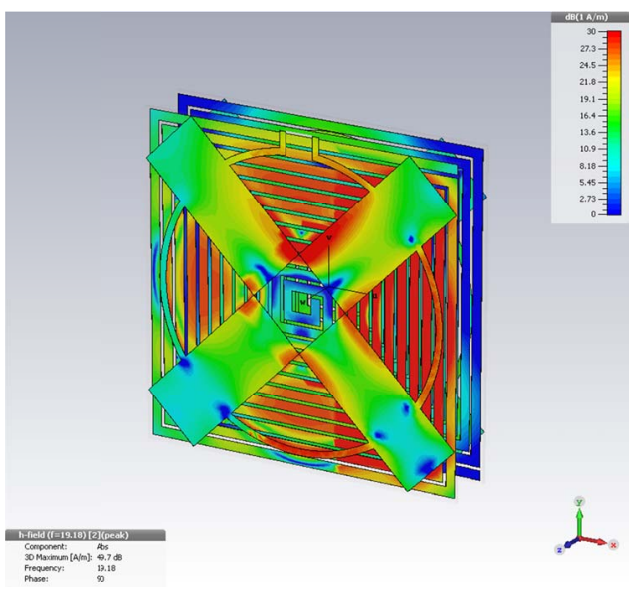

(20mm)

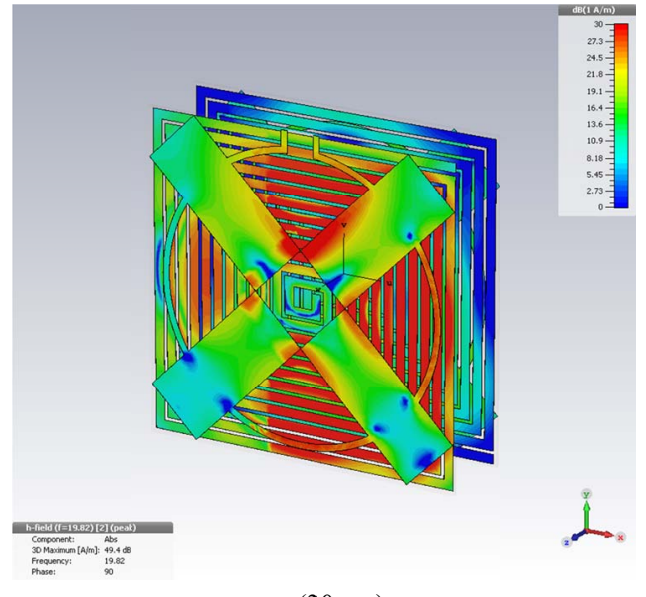

$(30 \mathrm{~mm})$
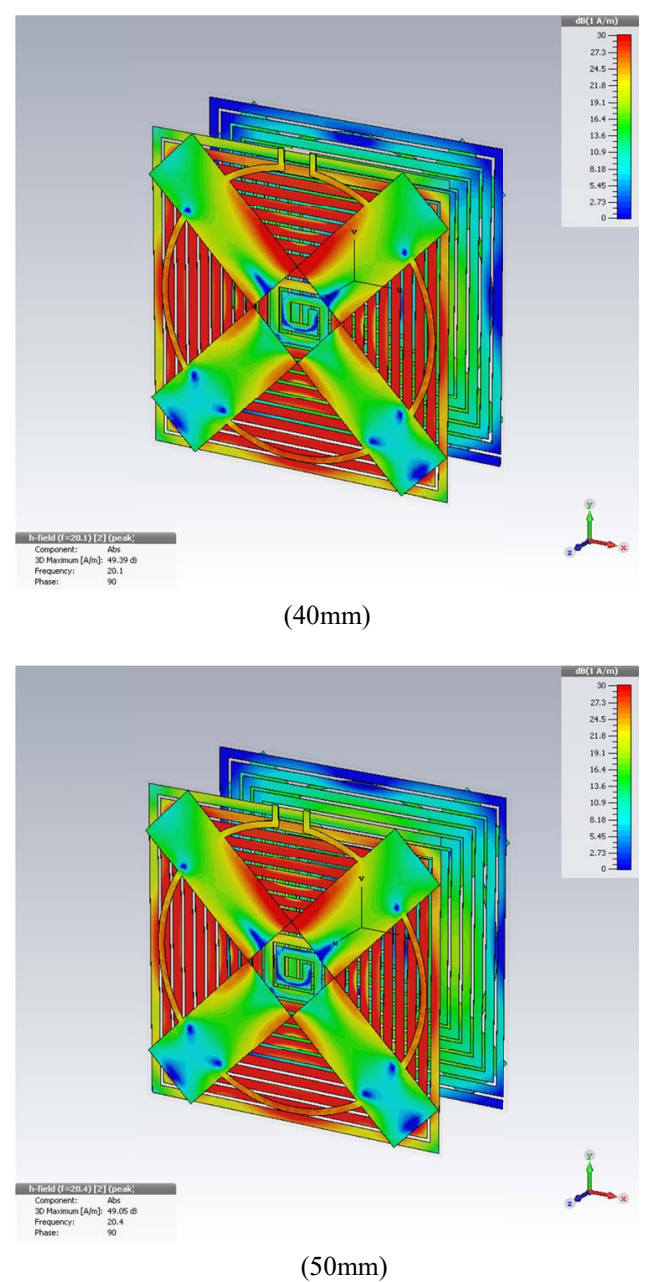

$(50 \mathrm{~mm})$ 

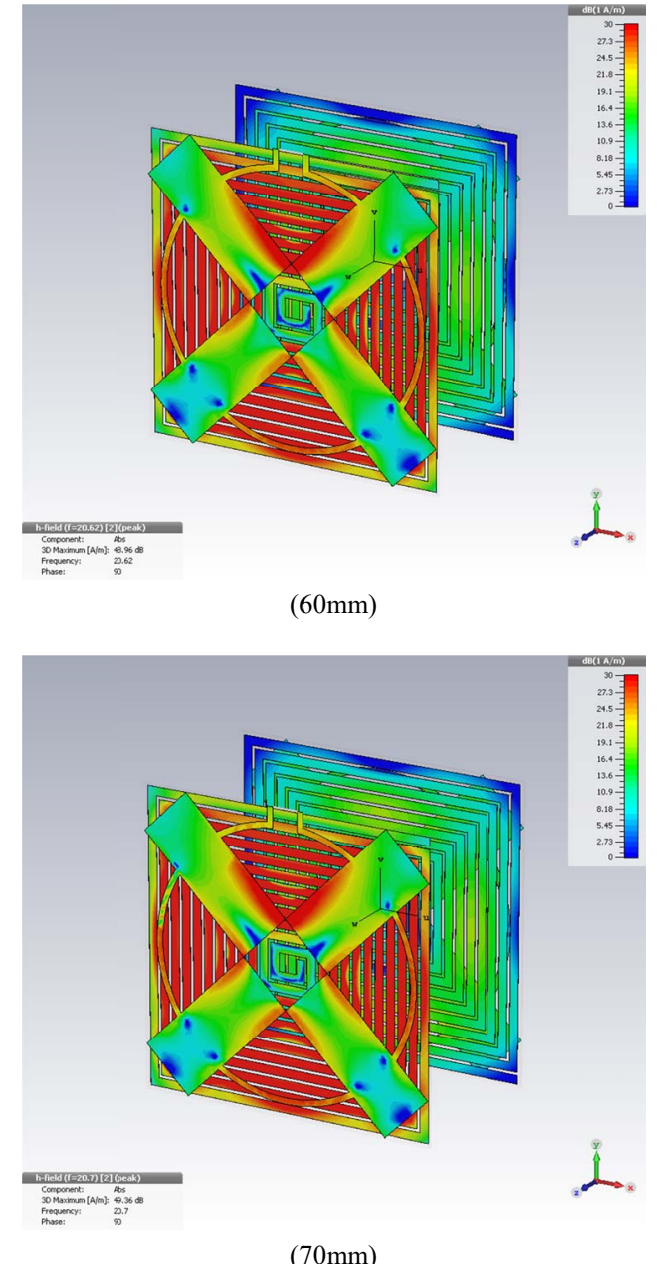

(70mm)

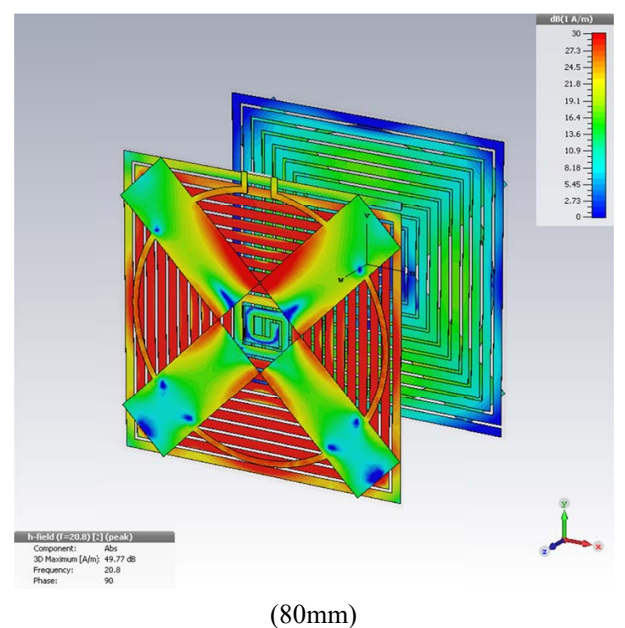

$(80 \mathrm{~mm})$

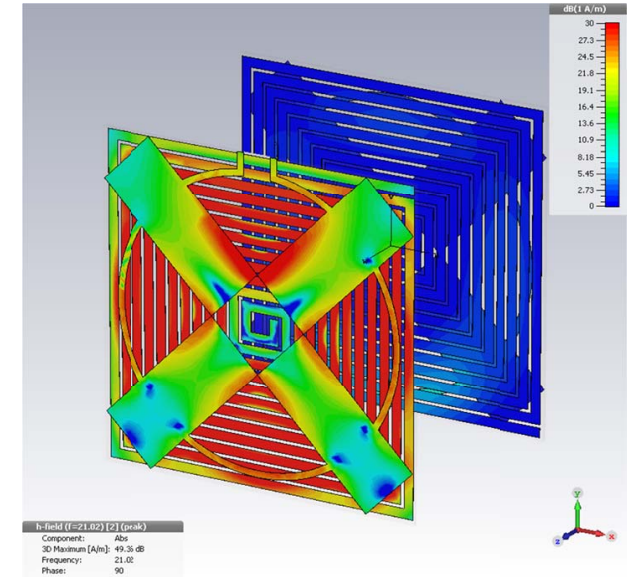

$(90 \mathrm{~mm})$

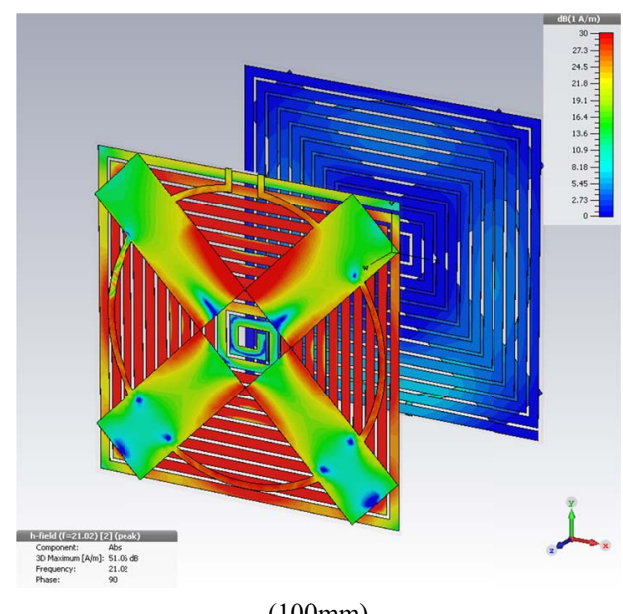

Fig. 8. Distribución de corriente superficial entre las antenas a distancias de $10 \mathrm{~mm}$ a $100 \mathrm{~mm}$

La más alta densidad de corriente superficial se observa a $10 \mathrm{~mm}$ de distancia, lo cual refleja el más alto valor de potencia recibido concentrada en el área media de la antena. A $20 \mathrm{~mm}$, la densidad de corriente decae levemente, se puede notar fácilmente en el área media del dispositivo que el color predominante es el azul que corresponde a una zona baja de $8 \mathrm{~dB}$. Entre $20 \mathrm{~mm}$ y $50 \mathrm{~mm}$, se observa un patrón similar en la corriente superficial con un eficiente acople magnético.

Con distancias de $60 \mathrm{~mm}$ a $80 \mathrm{~mm}$ se observa un intercambio de energía sostenible a pesar que se nota un ligero descenso en la transferencia. Finalmente, a los $90 \mathrm{~mm}$ y $100 \mathrm{~mm}$ se observa un drástico cambio en la densidad de corriente superficial con una cantidad más baja de corriente, lo cual indica que el sistema tiende a experimentar una menor ganancia de potencia para distancias mayores a $80 \mathrm{~mm}$.

\section{2) Parámetros $S$}

Para entender los parámetros de dispersión $-\mathcal{S}$ de manera numérica, $S_{n n}$, representa la potencia reflejada en el puerto $n^{\text {th }}$ de la antena radiadora, mientras que $S_{n n}$, representa la potencia transmitida desde el puerto $m^{\text {th }}$ al puerto $n^{\text {th }}$.

En la simulación, el puerto 1 está configurado como puerto de entrada (antena Tx) de potencia que ingresa al parche microstrip radiante y el puerto 2 actúa como puerto de salida 
en donde la potencia es obtenida inalámbricamente (antena $\mathrm{Rx}$ ). Si el valor de $S_{11}$ es muy bajo y el valor de $S_{21}$ es cercano a los $0 \mathrm{~dB}$, entonces significa que la antena radiante microstrip funciona apropiadamente y los valores de recepción inalámbricos son adecuados para alimentar el circuito de amplificación en la implementación, por tal razón, los valores $S_{11}$ y $S_{21}$ son los indicadores clave en la evaluación del rendimiento del sistema simulado.

En la Fig. 9 se presentan los valores de $S_{21}$ (es decir la cantidad de energía que sale desde el puerto $1-\mathrm{Tx}$ hasta el puerto $2-\mathrm{Rx}$ ) en valores lineales con el propósito de conocer en valores porcentuales el rendimiento del sistema.
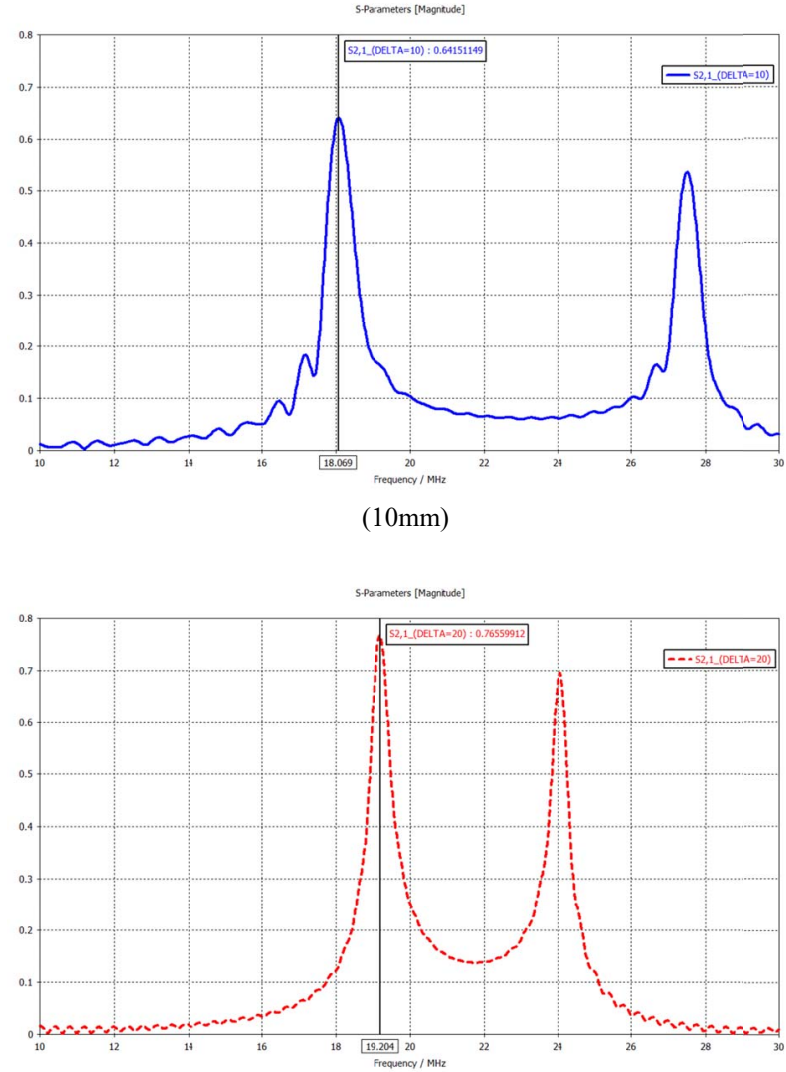

(20mm)

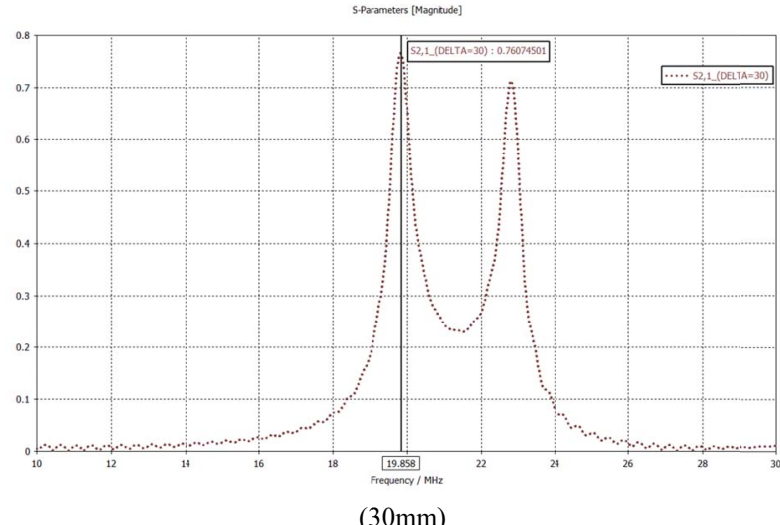

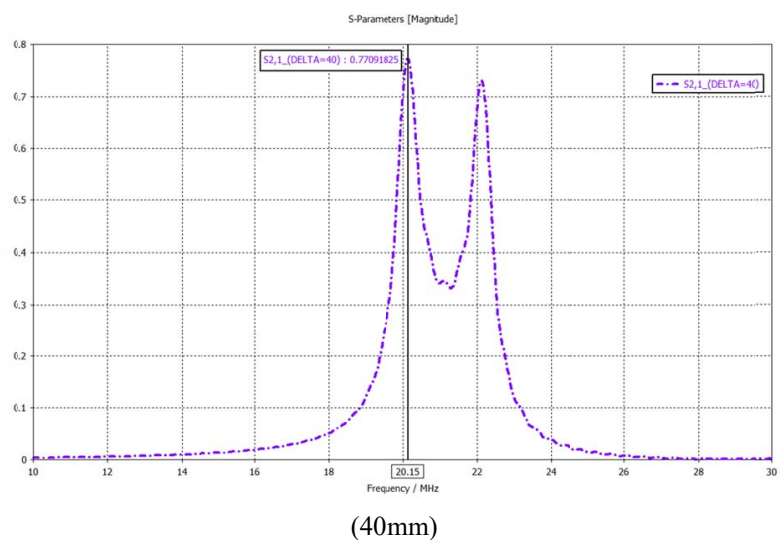
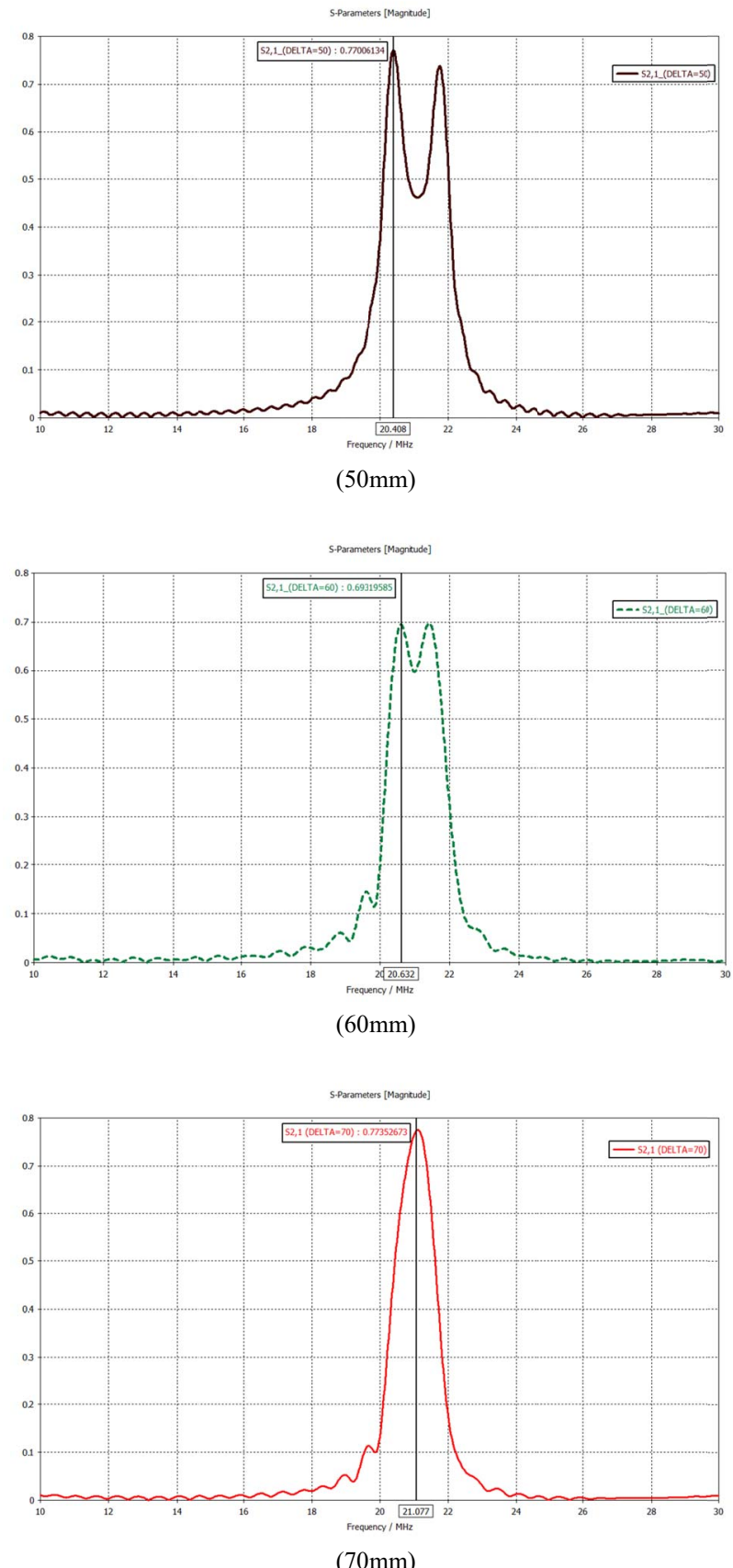

(70mm) 


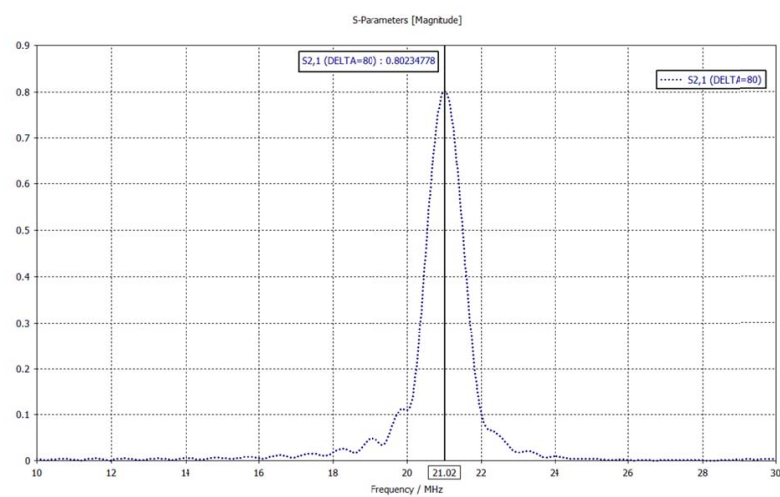

$(80 \mathrm{~mm})$

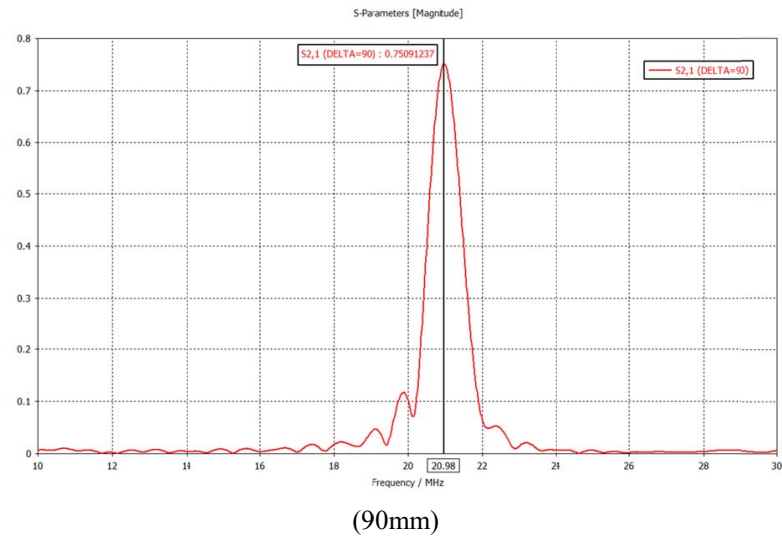

sposenten

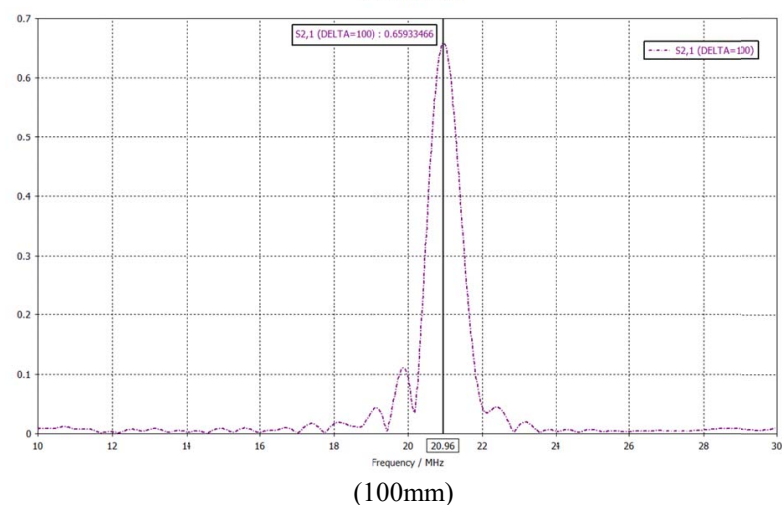

Fig. 9. Resultados simulados del sistema radiante para separaciones entre 10 y $100 \mathrm{~mm}$

Los resultados de los parámetros $-S$ obtenidos de la simulación se resumen en la Tabla 2.

De la Tabla 2 se observa que conforme se aumenta la distancia de separación entre las antenas radiantes su frecuencia de resonancia varía hasta el valor calculado con la ecuación (1) y en el cual debería trabajar si no estuviera en acoplamiento con otra antena. Se observa que a $10 \mathrm{~mm}$ por efectos de sobre acoplamiento, gran parte del campo magnético se refleja en dirección contraria a la definida lo que a la vez incide en un bajo porcentaje de eficiencia.
TABLA II

EFICIENCIA DE SISTEMA ACORDE A LA DISTANCIA DE SEPARACIÓN OBTENIDOS DE LA SIMULACIÓN

\begin{tabular}{llll}
\hline \hline $\begin{array}{l}\text { Distancia de } \\
\text { separación }(\mathrm{mm})\end{array}$ & $\begin{array}{l}\text { Frecuencia de } \\
\text { Operación }(\mathrm{MHz})\end{array}$ & $\mathrm{S}_{21}$ & $\begin{array}{l}\text { Eficiencia del } \\
\text { sistema } \eta_{21}(\%)\end{array}$ \\
\hline 10 & 18.069 & 0.6415 & 41.15 \\
\hline 20 & 19.204 & 0.7655 & 58.59 \\
\hline 30 & 19.858 & 0.7607 & 57.86 \\
\hline 40 & 20.15 & 0.7709 & 59.42 \\
\hline 50 & 20.408 & 0.7700 & 59.29 \\
\hline 60 & 20.632 & 0.6931 & 48.03 \\
\hline 70 & 21.12 & 0.7749 & 60.04 \\
\hline 80 & 21.02 & 0.8024 & 64.38 \\
\hline 90 & 20.98 & 0.7509 & 56.38 \\
\hline 100 & 20.96 & 0.6592 & 43.45 \\
\hline \hline
\end{tabular}

Por otra parte, se evidencia que entre $20 \mathrm{~mm}$ y $50 \mathrm{~mm}$ existe una eficiente transferencia de energía. También de las gráficas se desprende que el ancho de banda disminuye conforme la distancia aumenta.

En referencia a la Fig. 10 las curvas de los parámetros $-\mathcal{S}$ en las distancias comprendidas entre $10 \mathrm{~mm}$ y $100 \mathrm{~mm}$ indican que existe un buen acoplamiento en el sistema, nótese la línea de $-3 \mathrm{~dB}$ que muestra el rendimiento del $50 \%$ del sistema.

Los resultados de la simulación señalan que el mejor acoplamiento sucede entre los $20 \mathrm{~mm}$ y $50 \mathrm{~mm}$, con un pico máximo en los $40 \mathrm{~mm}$, eficiencia de $59.42 \%$ y un ancho de banda efectivo entre los $20.15 \mathrm{MHz}$ hasta los $22.2 \mathrm{MHz}$.

Se demuestra mediante la simulación que el sistema propuesto transfiere energía inalámbricamente hasta los $100 \mathrm{~mm}$ de distancia entre las antenas con más del $40 \%$ de eficiencia del acoplamiento.

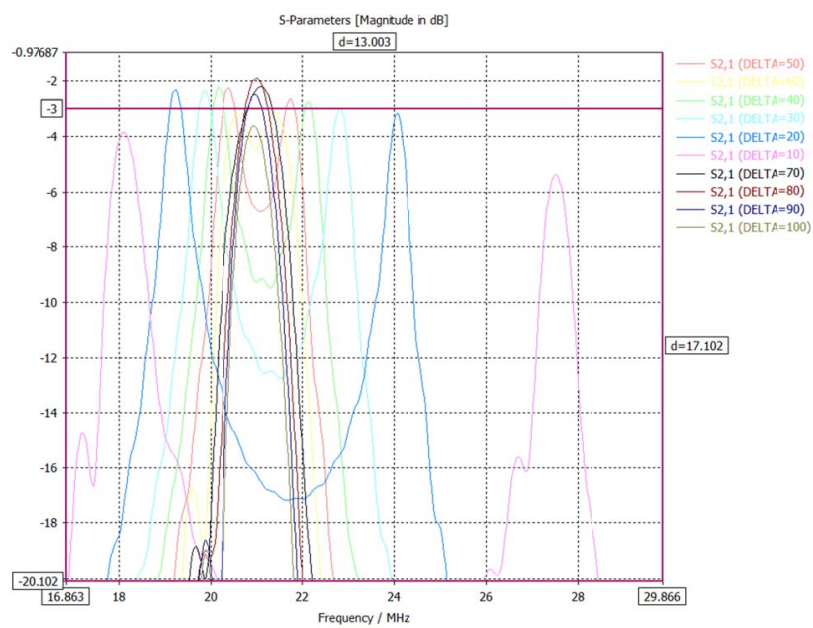

Fig. 10. Resultados simulados a distancias entre $10 \mathrm{~mm}$ a $100 \mathrm{~mm}$

\section{B. Implementación}

Se utilizaron conectores SMA hembras para las antenas con sus respectivos claves coaxiales. La señal fuente se aplicó únicamente a la espira que conecta a las placas capacitivas en $\mathrm{Tx}$, se procedió de la misma manera en el caso de la antena $\mathrm{Rx}$.

Las antenas fabricadas se muestran en la Fig. 11 soldadas a sus respectivos conectores coaxiales de radio frecuencia SubMiniature version A (SMA). 


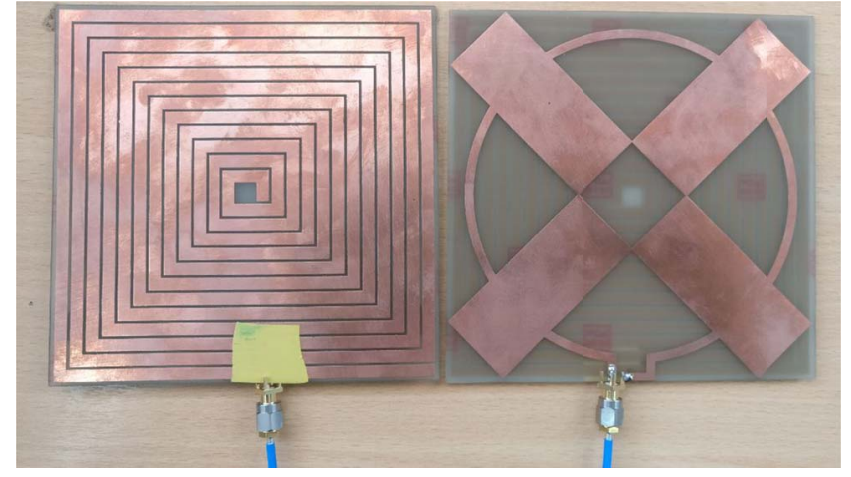

Fig. 11. Antenas impresas en el sustrato FR4

Las tomas de resultados del sistema de antenas se muestran en la Fig. 12.

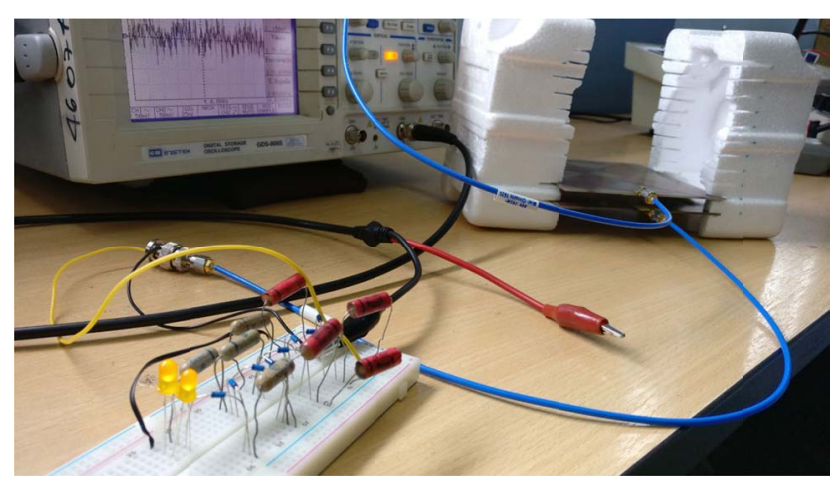

Fig. 12. Medición de los valores de voltaje transmitidos con un osciloscopio

Los valores obtenidos resultaron ser menores de lo esperado en comparación con la simulación.

La Tabla 3 mide la eficiencia del sistema según se varía la distancia sin obstáculos entre las antenas, se observa que el rendimiento decae conforme se aumenta la separación. La distancia con mejor transferencia es a $10 \mathrm{~mm}$.

TABLA III

EFICIENCIA DEL SISTEMA ACORDE A LOS DATOS TOMADOS DE LA IMPLEMENTACIÓN

\begin{tabular}{lllll}
\hline \hline $\begin{array}{l}\text { Distancia } \\
(\mathrm{mm})\end{array}$ & $\begin{array}{l}\text { Frecuencia de } \\
\text { transferencia } \\
\text { máxima }(\mathrm{MHZ})\end{array}$ & $\begin{array}{l}\text { Vpp Rx } \\
(\mathrm{mV})\end{array}$ & $\begin{array}{l}\text { Vpp Tx } \\
(\mathrm{mV})\end{array}$ & $\begin{array}{l}\text { Eficiencia } \\
\text { del sistema }\end{array}$ \\
\hline 10 & 15,7 & 4240 & 13500 & $31,41 \%$ \\
\hline 20 & 16,9 & 3620 & 13200 & $27,42 \%$ \\
\hline 30 & 17,5 & 3400 & 13200 & $25,76 \%$ \\
\hline 40 & 17,9 & 3260 & 13200 & $24,70 \%$ \\
\hline 50 & 18,1 & 3160 & 13100 & $24,12 \%$ \\
\hline 60 & 18,3 & 3080 & 12900 & $23,88 \%$ \\
\hline 70 & 18,5 & 3060 & 12800 & $23,91 \%$ \\
\hline 80 & 18,6 & 2940 & 12700 & $23,15 \%$ \\
\hline 90 & 18,7 & 2700 & 12600 & $21,43 \%$ \\
\hline 100 & 18,7 & 2340 & 12600 & $18,57 \%$ \\
\hline \hline
\end{tabular}

En la Tabla 4 y Fig. 14 se expone la tasa de error obtenida entre los resultados del sistema simulado e implementado. Se observa que la mayor tasa de error sucede a los $10 \mathrm{~mm}$ de distancia.
TABLA IV

TASA DE ERROR PORCENTUAL DE LOS VALORES SIMULADOS VS MEDIDOS

\begin{tabular}{llll}
\hline \hline $\begin{array}{l}\text { Distancia } \\
(\mathrm{mm})\end{array}$ & $\begin{array}{l}\text { Frecuencia de } \\
\text { transferencia } \\
\text { medida }(\mathrm{MHZ})\end{array}$ & $\begin{array}{l}\text { Frecuencia de } \\
\text { transferencia } \\
\text { Simulada }(\mathrm{MHZ})\end{array}$ & $\begin{array}{l}\text { Porcentaje de } \\
\text { error simulado } \\
\text { - medido }\end{array}$ \\
\hline 10 & 15,7 & 18 & $14,65 \%$ \\
\hline 20 & 16,9 & 19,2 & $13,61 \%$ \\
\hline 30 & 17,5 & 19,8 & $13,14 \%$ \\
\hline 40 & 17,9 & 20,1 & $12,29 \%$ \\
\hline 50 & 18,1 & 20,4 & $12,71 \%$ \\
\hline 60 & 18,3 & 20,6 & $12,57 \%$ \\
\hline 70 & 18,5 & 21.12 & $14.16 \%$ \\
\hline 80 & 18,6 & 21.02 & $13.01 \%$ \\
\hline 90 & 18,7 & 20.98 & $12.19 \%$ \\
\hline 100 & 18,7 & 20.96 & $12.09 \%$ \\
\hline \hline
\end{tabular}

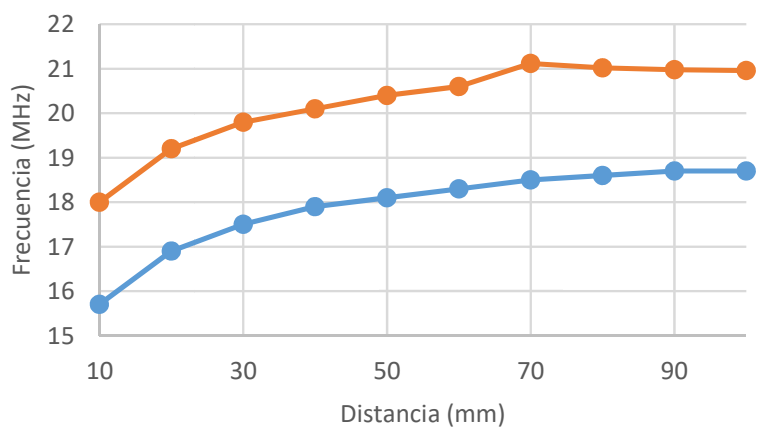

$\longrightarrow$ Frecuencia Medida (MHZ) —-Frecuencia Simulada (MHZ)

Fig. 13. Comparativa de los datos obtenidos de la simulación y la implementación del sistema de antenas de la frecuencia de resonancia acorde a la distancia

Para comprobar la versatilidad en la transmisión, el sistema se probó con varios tipos de materiales que sirven como obstáculos entre las antenas al representar además la implementación en proyectos prácticos como se expone en la Fig. 15.

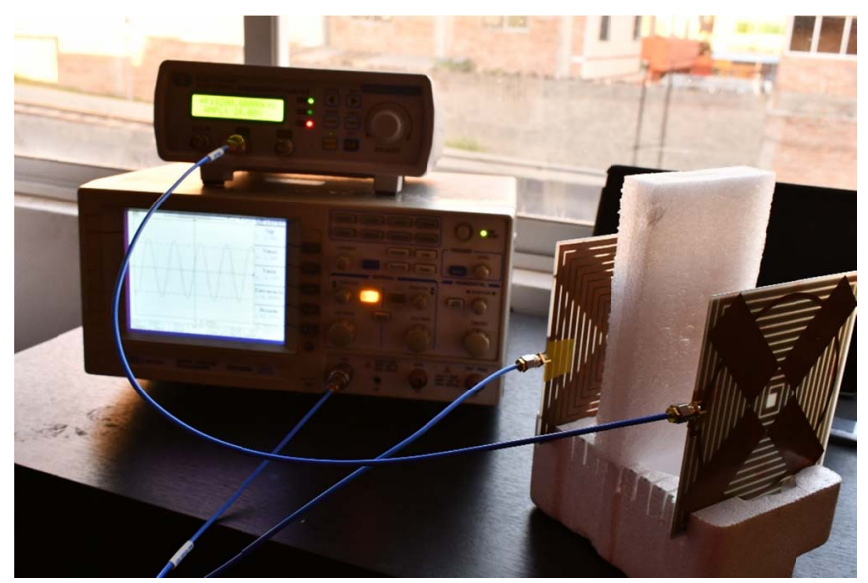

Fig. 14. Medición de la eficiencia del sistema al usar poli estireno expandido entre las antenas

En las Tablas 5 y 6 se presentan los resultados de la pérdida de eficiencia del sistema bajo los parámetros antes mencionados a distancias establecidas a criterio del autor de $30 \mathrm{~mm}$ y $100 \mathrm{~mm}$ respectivamente. 
TABLA V

EFICIENCIA DEL SISTEMA A 30MM DE SEPARACIÓN CON DISTINTOS MATERIALES ENTRE TX Y RX

\begin{tabular}{llllll}
\hline \hline Material & $\begin{array}{l}\text { Frecuencia } \\
\text { de trabajo }\end{array}$ & $\begin{array}{l}\mathrm{Vpp} \\
\mathrm{Tx} \\
(\mathrm{mV})\end{array}$ & $\begin{array}{l}\text { Vpp Rx } \\
(\mathrm{mV}) \\
\text { Sin } \\
\text { Material }\end{array}$ & $\begin{array}{l}\text { Vpp Rx } \\
(\mathrm{mV})\end{array}$ & $\begin{array}{l}\text { Con } \\
\text { Material }\end{array}$ \\
\hline Aglomerado & 17.5 & 13200 & 3300 & 3200 & $3.03 \%$ \\
\hline Plástico & 17.5 & 13200 & 3300 & 3300 & $0.00 \%$ \\
\hline Madera & 17.5 & 13200 & 3300 & 3080 & $6.67 \%$ \\
\hline Metal & 17.5 & 13200 & 3300 & 80 & $97.58 \%$ \\
\hline Vidrio & 17.5 & 13200 & 3300 & 3200 & $3.03 \%$ \\
\hline $\begin{array}{l}\text { Poli estireno } \\
\text { expandido }\end{array}$ & 17.5 & 13200 & 3300 & 3300 & $0.00 \%$ \\
\hline Tela & 17.5 & 13200 & 3300 & 3240 & $1.82 \%$ \\
\hline Cartón & 17.5 & 13200 & 3300 & 3300 & $0.00 \%$ \\
\hline \hline
\end{tabular}

TABLA VI

EFICIENCIA DEL SISTEMA A 100MM DE SEPARACIÓN CON DISTINTOS MATERIALES ENTRE TX Y RX

\begin{tabular}{|c|c|c|c|c|c|}
\hline Material & $\begin{array}{l}\text { Frecuencia } \\
\text { de trabajo }\end{array}$ & $\begin{array}{l}\text { Vpp } \\
\text { Tx } \\
(m V)\end{array}$ & $\begin{array}{l}\text { Vpp Rx } \\
(\mathrm{mV}) \\
\text { Sin } \\
\text { Material }\end{array}$ & $\begin{array}{l}\begin{array}{l}\text { Vpp Rx } \\
(\mathrm{mV})\end{array} \\
\text { Con } \\
\text { Material }\end{array}$ & Pérdida \\
\hline Aglomerado & 18.7 & 12600 & 2340 & 2300 & $1.71 \%$ \\
\hline Plástico & 18.7 & 12600 & 2340 & 2340 & $0.00 \%$ \\
\hline Madera & 18.7 & 12600 & 2340 & 2300 & $1.71 \%$ \\
\hline Metal & 18.7 & 12600 & 2340 & 640 & $72.65 \%$ \\
\hline Vidrio & 18.7 & 12600 & 2340 & 2300 & $1.71 \%$ \\
\hline $\begin{array}{l}\text { Poli estireno } \\
\text { expandido }\end{array}$ & 18.7 & 12600 & 2340 & 2340 & $0.00 \%$ \\
\hline Tela & 18.7 & 12600 & 2340 & 2320 & $0.85 \%$ \\
\hline Cartón & 18.7 & 12600 & 2340 & 2340 & $0.00 \%$ \\
\hline
\end{tabular}

Se observa que, con materiales como el aglomerado, plástico, vidrio, poli estireno expandido y tela, la eficiencia sufre mínimas perdidas y logra transmitir la energía inalámbrica sin problema alguno.

En el caso de la madera se observa una baja en el rendimiento del $6.67 \%$ que se debe tomar en cuenta para la implementación del sistema en un mueble de este material para no tener pérdidas indeseables en el lado del receptor.

Por otra parte, al utilizar metal como obstáculo se obtiene una pérdida total de la transmisión.

\section{CONCLUSIONES}

Se construyó un sistema que permite la transmisión inalámbrica de energía eléctrica al usar placas FR4 de fácil adquisición como antenas, además del uso de integrados MMIC para la fuente de energía y diodos Schottky para la rectificación y amplificación de la señal transmitida. Se evidencia que, en el sistema a menor distancia de separación entre las antenas existe una mejor eficiencia, al comprobar que, a una separación de $10 \mathrm{~mm}$ se obtiene un rendimiento del $31.41 \%$ del voltaje transmitido, con lo que decae al $18.57 \%$ a una separación de $100 \mathrm{~mm}$. Mediante la simulación, se observó que al variar aspectos en el material dieléctrico como el espesor o la permitividad eléctrica se puede crear antenas con un tamaño más reducido que el propuesto, debido a que mejores valores de permitividad eléctrica del sustrato mejoran la calidad de transferencia eléctrica con menor cantidad del material. Se determinó que la distancia óptima de funcionamiento del sistema sin obstáculos comprende desde los $10 \mathrm{~mm}$ hasta los $50 \mathrm{~mm}$ con un valor promedio de recepción de $26.68 \%$ del voltaje transmitido. La mayor aportación del proyecto se centra en la versatilidad que provee el sistema, porque, al incorporar la antena transmisora a una surtida cantidad de mobiliario se facilita la carga eléctrica de gadgets de baja potencia con un simple acercamiento.

\section{REFERENCIAS}

[1] Naoki Shinohara. (2014). Wireless Power Transfer via Radiowaves. Wiley

[2] Agbinya, J.I. (2012). Wireless Power Transfer. River Publishers

[3] A. Munir, and B. T. Ranum, (2015), "Wireless Power Charging System for Mobile Device Based on Magnetic Resonance Coupling", in Proc. of the $5^{\text {th }}$ International Conference on Electrical Engineering and Informatics, Aug. 10-11, Bali, Indonesia, pp. 221-224.

[4] J. Zhang and Z. Jia, (Dec. 2010), "Design of Voltage Doubling Rectifier Circuit in Wireless Sensor Networks," in Proceeding of International Conference on PIC, Sanghai, China, pp. 456 - 459.

[5] A. K. André Kurs, R. Moffat, J. D. Joannopoulos, P. Fisher, M. Soljiac (2007) "Wireless Power Transfer via Strongly Coupled Magnetic Resonances", Science AAAs. 83 - 85 .

[6] F. Pelliteri, V. Boscaino, R. L. Rosa, and G. Capponi, (2012), "Improving the Efficiency of a Standard Compliant Wireless Battery Charger," in Universities Power Engineering Conference (UPEC), 2012 $47^{\text {th }}$ International, pp. $1-6$.

[7] M. Kline, I. Izyumin, B. Boser, and S. Sanders, (2011), "Capacitive Power Transfer for Contactless Charging," in Applied Power Electronics Conference and Exposition (APEC), 2011 Twenty - Sixth Annual IEEE, pp. $1398-1404$

[8] X. Lu, P. Wang, D. Niyato, D. I. Kim and Z. Han, (2016), "Wireless Charging Technologies: Fundamentals, Standards, and Network Applications," in IEEE Communications Surveys \& Tutorials, vol. 18, no. 2, pp. 1413-1452.

[9] R. M. Dickinson, (1976), "Performance of a high-power, 2.388-GHz receiving array in wireless power transmission over $1.54 \mathrm{~km}$ ", in Proceeding of IEEE-MTT-S International Microwave Symposium (IMS), Chery Hill, USA, Jun, pp. $139-141$.

[10] M. H. M. Salleh, N. Seman, and D. N. A. Zaidel, (2014), "Design of a Compact Planar Witricity Device with Good Efficiency for Wireless Applications", Proceedings of Asia - Pacific Microwave Conference, pp. $1369-1371$.

[11] H. M. G. E. D. M. El-Anzeery, M. A. E. A. S. El-Bagouri, and R. Guindi, (2012), "Novel Radio Frequency Energy Harvesting Model," in Power Engineering and Optimization Conference (PEDCO), Melaka, Malaysia, 2012 IEEE International, pp. $209-213$.

[12] M. H. M. Salleh, N. Seman, and R. Dewan, "Reduced - Size Witricity Charger Design and its Parametric Study," IEEE International RF and Microwave Conference (RFM2013), Dec. 09 - 11, Penang, Malaysia, pp. $387-390$.

[13] S. L. Ho, J. Wang, W. N. Fu, M. Sun, "A Comparative Study Between Witricity and Traditional Inductive Magnetic Coupling in Wireless Charging," IEEE Transactions onMagnetics, vol. 47, no. 5, pp. $1522-$ 1525, May. 2011.

[14] X. Zhang, S. LHo., W.N. Fu, (2011), "Quantitative Analysis of a Wireless Power Transfer Cell with Planar Spiral Structures," IEEE Transactions on Magnetics, vol. 47, no. 10, pp. 3200-3203.

[15] B. T. Ranum, N. W. D. E. Rahayu, and A. Munir, "Characterization of Wireless Power Charging Receiver for Mobile Device," International Journal of Electrical Engineering and Informatics, vol. 7, no. 1, pp. 130 - 139, Mar. 2015

[16] D.G.Nottiani, F.Leccese, (2012), “A Simple Method for Calculating Lumped Parameters of Planar Spiral Coil for Wireless Energy Transfer," $11^{\text {th }}$ International Conference on Environment and Electrical Engineering (EEEIC), vol., no., pp. $869-872$.

[17] J. Wang, S.L. HO, W.N. Fu, M. Sun, (2010), "Finite Element Analysis and Corresponding Experiment of Resonant Energy Transmission for Wireless Transmission Device using Witricity," $14^{\text {th }}$ Biennial IEEE Conference onElectromagnetic Field Computation (CEFC), on, vol., no., pp. 1,1 . 
[18] J. Wang, S.L.Ho, W.N. Fu, M. Sun, (October 2011), “ Analytical Design Study of a Novel Witricity Charger with Lateral and Angular Misalignments for Efficient Wireless Energy Transmission," IEEE Transactions onMagnetics, vol.47, no.10, pp. 2616-2619.

[19] W. Peng, G. Zhao, (2012), "Experimental Analysis on Wireless Power Transmission Based on Magnetic Resonant Coupling," $2^{\text {nd }}$ International Conference onRemote Sensing, Environment and Transportation Engineering (RSETE), vol., no., pp. 1,4.

[20] N.W.D.E.Rahayu, A. Munir, (August 2014), "Radiator for Wireless Charging Application Based on Electromagnetic Coupling Resonant ," Proceeding of International Conference on Electrical Engineering, Computer Science and Informatics (EECSI 2014), Yogyakarta, Indonesia, pp. 496 - 499, 20-21.

[21] H.Zhou, S.Yang, (2012), "Resonant Frequency Calculation of Witricity Using equivalent Circuit Model Combined with Finite Element Method," International Conference onElectromagnetic Field Problems and Applications (ICEF), 2012 Sixth, vol., no., pp.1,4.

[22] F. Zhang, S.A. Hackwoth, X. Liu, C. Li, M. Sun, (2010), "Wireless Power Delivery for Wearable Sensors and Implants in Body Sensor Networks," Annual International Conference of the IEEE onEngineering in Medicine and Biology Society (EMBC), vol., no., pp. 692,695.

[23] X. Sun, M. Cao, J. Hao, Y. Guo, (2012), "A Rectangular Slot Antenna with Improved Bandwidth," AEU - International Journal of Electronics and Communications, vol. 66, pp.465-466,6.

[24] Xiu Zhang, S. L. Ho and W. N. Fu, (2010), "Modeling and design of a wireless power transfer cell with planar spiral structures," Digests of the 2010 14th Biennial IEEE Conference on Electromagnetic Field Computation, Chicago, IL, pp. 1-1.

[25] Martin Dadić, Karlo Petrović, Roman Malarić, (2017), "FEM Analysis of a PCB Integrated Resonant Wireless Power Transfer," 40th International Convention on Information and Communication Technology, Electronics and Microelectronics (MIPRO), Opatija, pp. 166-170.

[26] Johnson I. (2011). Agbinya. Principles of Inductive Near Field Communications for Internet of Things. River Publishers

[27] Iulian Rosu (2014), Microstrip, Stripline, and CPW Design 